\title{
Public International Law in the Situation of a Pandemic
}

\author{
Sarmad Amer Abbas \\ Assist. Prof. Dr., University of Babylon/Faculty of Law/Iraq
}

\begin{abstract}
In recent years, there have been considerable developments in international law with respect to the normative definition of the right to health, which includes both health care and healthy conditions. These norms offer a framework that shifts the analysis of issues such as disparities in treatment from questions of quality of care to matters of social justice. Building on work in social epidemiology, a rights paradigm explicitly links health with laws, policies, and practices that sustain a functional democracy and focuses on accountability.
\end{abstract}

Keywords: Public international, situation, pandemic.

\section{Introduction}

International health law, or what is now also called global health law, is a relatively new academic field. In its broadest definition, it includes all international legal regimes relevant to public health-international environmental law, international humanitarian and human rights law, international trade and labor law ${ }^{1}$, international laws relating to arms control, and so on. Construed more narrowly, it incorporates only those international legal regimes specifically designed to address health threats. The two most notable examples are the International Health Regulations (focused on infectious diseases) and the World Health Organization's (WHO) Framework Convention on Tobacco Control (FCTC) (focused on chronic diseases). There is an important distinction between international health law and global health law. International health law connotes a more traditional approach derived from rules governing relations among nation-states. Global health law, on the other hand ${ }^{2}$, is developing an international structure based on the world as a community, not just a collection of nation-states. This structure is inclusive of individuals and nongovernmental organizations ${ }^{3}$, especially where health problems are seen as truly global. Globalization has heightened the need for worldwide public health cooperation.International health law developed originally in the mid-nineteenth century to control infectious diseases and has transformed over time to include multiple norms and standards and to become a significant component of foreign policy ${ }^{4}$. Amidst these changes, however, a lack of normative theory has left the field without a basis for justice or common ground on the ethics and governance of threats to global health. Moreover, research to date has neglected normative problems, as well as the role of global health justice in addressing such problems, especially in establishing moral norms that guide the roles of international and domestic law as tools of public health.

WHO law for international regulation of international epidemics: A central and historic responsibility for the World Health Organization (WHO) has been the management of the global regime for the control of the international spread of disease. Under Articles 21(a) and 22, the Constitution of WHO confers upon the World Health Assembly the authority to adopt regulations "designed to prevent the international spread of disease" which, after adoption by the Health Assembly, enter into force for all WHO Member States that do not affirmatively opt out of them within a specified time period. In consideration of the growth in international travel and trade, and the emergence or re-emergence of international disease threats and other public health risks, the Forty-eighth World Health Assembly in 1995 called for a substantial revision of the Regulations adopted in 1969. In resolution WHA48.7, the Health Assembly requested the Director-General to take steps to prepare their revision, urging broad participation and cooperation in the process. After extensive preliminary work on the revision by WHO's Secretariat in close consultation with WHO Member States, international organizations and other relevant partners, and the momentum created by the emergence 
of severe acute respiratory syndrome (the first global public health emergency of the 21 st century), the Health Assembly established an Intergovernmental Working Group in 2003 open to all Member States to review and recommend a draft revision of the Regulations to the Health Assembly. The IHR (2005) were adopted by the Fifty-eighth World Health Assembly on 23 May 2005. They entered into force on 15 June 2007.

International Health Regulations (IHR): The International Health Regulations (IHR 1969), replaced by IHR 2005 had been adopted by the World Health Assembly on 23 May 2005 and came into force on 15 June 2007. IHR 2005 are a legally binding agreement among World Health Organization (WHO) member states and other states that have agreed to be bound by them. New revision was necessitated by concerns about increasing global health threats and the need to respond with more effective surveillance and control practices. The limitations of IHR 1969, which led to their revision, related to their narrow scope, their dependence on official country notifications, and their lack of a formal internationally coordinated mechanism to contain international disease spread. ${ }^{5}$ The IHR 2005, which is firmly based on practical experiences, has broaden the scope of IHR 1969 to cover existing, new and reemerging diseases, including emergencies caused by non-infectious disease agents.

The purpose and scope of the IHR (2005) are "to prevent, protect against, control and provide a public health response to the international spread of disease in ways that are commensurate with and restricted to public health risks, and which avoid unnecessary interference with international traffic and trade." The IHR (2005) contain a range of innovations, including: (a) a scope not limited to any specific disease or manner of transmission, but covering "illness or medical condition, irrespective of origin or source, that presents or could present significant harm to humans"; (b) State Party obligations to develop certain minimum ${ }^{6}$ core public health capacities; (c) obligations on States Parties to notify WHO of events that may constitute a public health emergency of international concern according to defined criteria; (d) provisions authorizing WHO to take into consideration unofficial reports of public health events and to obtain verification from States Parties concerning such events; (e) procedures for the determination by the Director-General of a "public health emergency of international concern" and issuance of corresponding temporary recommendations, after taking into account the views of an Emergency Committee; (f) protection of the human rights of persons and travellers; and $(\mathrm{g})$ the establishment of National IHR Focal Points and WHO IHR Contact Points for urgent communications between States Parties and WHO.

This approach has roots in Aristotle's political theory and Amartya Sen's capability approach, but it moves extensively beyond and considerably extends this work for national and global health purposes. From this perspective, health is intrinsically and instrumentally valuable; all individuals should have equal capability to be healthy. It takes the individual as the central moral unit of justice?

Under this approach, if we value, intrinsically and instrumentally, individuals' capabilities to be healthy, we regard deprivations of health capabilities as inequalities in individuals' capabilities to function. Decrements in a person's health constitute direct threats to his or her well-being and agency. Health capabilities are therefore prerequisites to other capabilities, and their moral importance calls for a sense of urgency ${ }^{8}$. From this perspective, a global society and its constituent nationstates must address global health inequalities and global threats to human health. Primary moral responsibility falls on nation-states, within which health inequalities and the sources of health threats lie.

Achieving global health equity requires global law and policy to strengthen the capacities and wills of domestic institutions, laws, and policies to address health issues within their countries; the future of global health law cannot be examined or understood as separate from domestic health law and policy. Global health law and policy also have key roles in the development and internalization of public moral norms to create and sustain health institutions, policies, and laws in the long term.

Full compliance with international health regulations: The International Health Regulations, the principle document governing the response to public health emergencies that pose an international threat, were revised in 2005 and became binding international law on June 15, 2007. These new regulations, unanimously approved by the World Health Assembly, differ in important ways from previous versions and represent a major step forward in protecting global public health security. Despite their importance, countries will face several challenges to implementing the regulations. 
Many developing countries lack the capacity to detect and respond to public health emergencies, and developed countries may choose to act unilaterally. Decentralized states such as Canada will also face specific challenges to implementation. In May 2008, the Auditor General of Canada issued a report highlighting areas in which Canada has had difficulty complying with the new regulations.

The goal of the revised International Health Regulations are to protect against the international spread of epidemics and other public health emergencies without unnecessary interference with international travel and trade. To achieve this objective, the regulations provide new guidance to member states on several matters. The fundamental premise of the regulations is that preparation and early detection and response are essential to protect against global health emergencies ${ }^{8}$. The regulations therefore require member states to assess their core capacity for effective public health surveillance and response within 2 years and meet requirements for core capacity within the subsequent 3 years.

The revised International Health Regulations have been criticized for subordinating health concerns to security and economic concerns. They have also been described as overemphasizing surveillance not placing enough emphasis on assistance for developing countries 13 and lacking a legal mechanism to ensure compliance ${ }^{9}$.

Despite these criticisms, the new regulations were unanimously approved by the WHO member states. All member states are bound by their requirements unless they specifically objected to them by the end of 2007 . As of February 2008, no member states had rejected the regulations, 188 had designated National Focal Points, 76 had already conducted an assessment of their national core capacities, and 50 had nominated individuals to the International Health Regulations Roster of Experts. A number of countries, including Australia, Syria, Finland, Sweden, Columbia, France, Georgia and Germany, have already recognized the regulations as domestic law or have incorporated elements of the agreement into their national health legislation. A number of other countries, including Argentina, Spain, Brazil, South Africa and the European Community, have passed administrative regulations that cite the new International Health Regulations. Still other countries, including the United Kingdom are considering "all-hazards" approaches to the reform of their public health legislation. In spite of these efforts and the recognition of the importance of the regulations, several factors may prevent full national compliance. This is particularly true when compliance may leave countries, or regions within countries, vulnerable.Nevertheless, Under international law, there is a right not merely to health care but to the much broader concept of health. Because rights must be realized inherently within the social sphere, this formulation immediately suggests that determinants of health and ill health are not purely biological or "natural" but are also factors of societal relations. Thus, a rights perspective is entirely compatible with work in epidemiology that has established social determinants as fundamental causes of disease. The first notion of a right to health under international law is found in the 1948 Universal Declaration of Human Rights (hereafter called Declaration), which was unanimously proclaimed by the UN General Assembly as a common standard for all humanity. The Declaration sets forth the right to a "standard of living adequate for the health and wellbeing of himself and his family, including ... medical care and ... the right to security in the event of . . . sickness, disability . . . or other lack of livelihood in circumstances beyond his control. The Declaration does not define the components of a right to health; however, they both include and transcend medical care.

The language of progressive realization and maximal available resources, which suggests different standards for different countries, does not easily jibe with the absoluteness with which people in the world generally think about rights. Yet in practice, due process and other civil rights may vary just as much. Indeed, the egregious disparities among countries, suggest not the irrelevance of defining a right to health but rather the need to situate state obligations within a global political economy in which international institutions and thirdparty states often exercise inordinate influence over developing countries' economies and policies. The right to health demands, as do all human rights, "international assistance and cooperation.

The reference to a "highest attainable standard" of health, taken from the World Health Organization constitutionbuilds in a reasonableness standard. That is, the state has a role to play in leveling the social playing field with respect to health; however, there are factors that are beyond the state's control.1,10,11 Furthermore, the highest attainable standard will necessarily evolve over time, in response to medical inventions, as well as demographic, epidemiological, and economic shifts. 
In addition to the ICESCR, a wide array of international and regional treaties recognizes health as a rights issue, and these reflect a broad consensus on the content of the norms. A review of the international instruments and interpretive documents makes it clear that the right to health as it is enshrined in international law extends well beyond health care to include basic preconditions for health, such as potable water and adequate sanitation and nutrition.

Realization of the right to health further implies providing individuals and communities with an authentic voice in decisions defining, determining, and affecting their well-being. Public health has a long tradition of recognizing that participation is integral to health promotion.21 Further, analyses of the importance of structural determinants of health and political economic context are increasingly common. Framing health as a right adds to the growing literature in social epidemiology that links health with social justice; it does this by first making explicit the link between health and the construction of a functional democracy. That is, health-related resource distribution, evidence of discrimination and disparities, and the like are analyzed not just in terms of their impact on health status but also their relation to laws, policies, and practices that limit popular participation in decision-making and, in turn, the establishment of a genuinely democratic society.

Failure to respect, protect, or fulfill responsibilities relating to health are construed not only in terms of ensuing social or economic problems, but also explicitly in terms of the accountability of the state and, to a certain extent, other actors, under national and international law1,6,10-12,26 Thus, a human rights framework simultaneously acknowledges health as inherently political-intimately bound up with social context, ideologies, and power structures - and removes health policy decisions from being matters of pure political discretion by placing them squarely into the domain of law.

\section{Conclusions}

This Essay has argued that the global community has an ethical and moral responsibility to take positive actions to achieve health equity and should do so through global and domestic tools in law, policy, and institutions. It has presented a set of normative principles - moral foundations - for global health law as guidance on critical health issues. It has argued that, while legal principles have existed over the past several centuries, a coherent set of normative principles, grounded in moral theory, has been lacking. This approach does not argue that the global community has an enforceable (coercible) legal duty. Rather, it envisions global health law embedded in a framework of global health governance, whose purpose is realizing global health equity. It achieves its purpose through the voluntary internalization of the public moral norm of health equity and through subsequent domestic law and policy development and implementation.

Public health officials have recognized the importance of collective action to manage international health emergencies. If countries fail to act, or act independently, it will result in a less than optimal response that will increase the harms to their citizens and disrupt the global economy. Compliance with the revised International Health Regulations is a critical step toward preventing this from happening. Canada, a key advocate for the regulations, should lead the way both by demonstrating its own compliance with the regulations and by championing their implementation in all countries.

Financial Disclosure: There is no financial disclosure.

Conflict of Interest: None to declare.

Ethical Clearance: All experimental protocols were approved under the University of Babylonand all experiments were carried out in accordance with approved guidelines.

\section{References}

1. David P. International Law and Public Health: Material on and Analysis of Global Health Jurisprudence. 2000.

2. FidlerDP. Caught Between Paradise and Power: Public Health, Pathogenic Threats, and the Axis of Illness. Mc George L. Rev. 2004;35:45, 55-72.

3. Jennifer PR. Normative Foundations of Global Health Law, Georgetown Law J. 2008; 96(2): 423443.

4. International Health Regulations, Third Edition, World Health Organization, 2016; 1-2.

5. Jennifer PR. Ethics of the Social Determinants of Health, 364 Lancet 1092 (2004) [hereinafter Ruger, Ethics of the Social Determinants of Health]; Jennifer PrahRuger, Health, Capability, and Justice: 
Toward a New Paradigm of Health Ethics, Policy and Law, 15 Cornell J.L. \& Pub. Pol'y 403. 2006

6. Krieger N. Does racism harm health? Did child abuse exist before 1962? On explicit questions, critical science, and current controversies: an eco-social perspective. Am J Public Health. 2003;93:194-199.

7. Krieger N, Gruskin S. Frameworks matter: ecosocial and health and human rights perspectives on disparities among women's health - the case of tuberculosis. J Am Womens Assoc. 2001;56:137142.

8. Marks S. The new partnership of health and human rights. Hum Rights Dialogue. 2001;2:21-22.
9. World Health Organization. Constitution. Geneva, Switzerland: World Health Organization; 1946.

10. Chapman A. Core obligations related to the right to health. In: Chapman A, Russell S, eds. Core Obligations: Building a Framework for Economic, Social and Cultural Rights. New York, NY: Intersentia; 2002:85-216.

11. International Convention on the Elimination of All Forms of Racial Discrimination. New York, NY: United Nations; 1966.

12. UN Committee on Economic, Ibid. See also. Kinney E. The international right to health: what does this mean for our nation and our world? Indiana Law Rev. 2001;34:1457-1475 